\title{
Idiosyncratic Remarks by a Bibliomaniac 2: Contrasts in Publishing and Markets
}

\begin{abstract}
He was literally surrounded by books. As far as his gaze could reach, there were books and still more books. The mere thought of even reading a fraction of them numbed his literary faculties ... . He found himself unwilling to open the cover of even one of them. He thought of giant forests denuded for the sake of these books; of millions of publishers and editors crushed beneath the weight of their spring and fall lists, of numberless bookstore owners resorting to theft and murder or else going mad in their efforts to keep from sinking in the seas of bankruptcy beneath the steadily rising tide of current fiction. He thought of haggard-eyed book reviewers turning their bitter faces to those strange and awful gods to which book reviewers are forced to turn in the affliction of their tortured brains. $\mathrm{He}$ heard abandoned men calling in loud voices for a momentary recession, at least, of the soul-rotting flood of books. He even though of authors, and his heart was filled with indignation against that indefatigable, ever hopeful tribe of word vendors.
\end{abstract}

Th. Smith, "Rain in the Doorway", Doubleday, 1933

These were the lines, especially the second but last, I first thought of when, on Wednesday, February 12, there arrived, unsolicited, unexpected, and unannounced, some 20 books, recently published in the U.S.S.R., for review in this journal. On the other hand, some of the best books in mathematics are written in the U.S.S.R., by some of the best mathematicians in the world; not all of these manuscripts get published. Also these books sell briskly. They sell fast partly because thinking about it often means you will be too late; especially in Moscow and Leningrad* ${ }^{*}$. And they sell in quantity. Print-runs have gone down considerably in the last ten years or so but still a high-level advanced monograph/textbook like B.A. Dubrovin, S.P. Novikov, A.T. Fomenko, Modern geometry: methods of homology theory, Nauka, 1984, had a print-run of 9300, and of S.P. Novikov a.o., Theory of Solitons: the method of inverse problems, Nauka, 1980, 5000 copies were printed. I wonder how many copies were produced of the (very bad) translation (Plenum, 1984) of the latter; probably around a thousand. Of the Russian Encyclopaedia of Mathematics in five volumes 150000 were printed and it has sold out completely. The publisher of the revised, updated, and augmented English translation of this work (D. Reidel Publishing Company) cannot even dream of such figures (and be considered more or less sane). Of course it is argued that books are cheap in the U.S.S.R. And so they are. An average price of 7 roubles and a bit per volume for the encyclopaedia works out at something like

* This results partly from an interesting rigid quota system that assigns fixed percentages of print runs to the various regions. These percentages were set long ago. 
$\$ 10$ or $\$ 11$. On the other hand, 7 roubles is something between 3 and $4 \%$ of a monthly salary and on that scale the equivalent is more like $\$ 110$ per volume. A considerable investment, but one which is made as a matter of course. Different standards and habits, reflecting a tradition which produces many top scientists and mathematicians who are formidable scholars as well.

Let me turn to some of the books from that tradition and some of their Western counterparts. As in the first column, these lines are written as if the author were browsing through a bookstore, weighing such incompatible ponderabilia and imponderabilia as limited budgets, scientific values and the cost of a wrong decision versus a delayed one or no decision at all.

V.I. Arnol'd, Catastrophe theory, Springer-Verlag, 1984, 79 pp., DM 16.80.

The original of this appeared in the series Znanie (Matematika, Kibernetika) as the September 1981 volume of this monthly popular science series of booklets. Price 0.11 roubles. Another, later one, in this series of booklets was by Yuri Manin and a translation was published by Birkhäuser. Title: Mathematics and Physics. This may give an idea of the high standards of the various Znanie series and it is to be hoped that many more will become available in English at reasonable prices, such as this delightful one by Arnol'd. Here is the list of titles of the last 9 issues of 1981 (the last year I had a subscribtion to the series): Yu. A. Danilov, John von Neumann, A.N. Kolmogorov, V.V. Vavilov, I.T. Tropin, The physical-mathematical school of Moscow State University, B.V. Gnedenko, From the history of randomness; Contemporary problems in mathematics, a volume containing translations of A.S. Eddington (Theory of groups, In: J.R. Newman, The world of mathematics Vol. 3 ), R.H. Bing (Point set topology, In: Insight into modern mathematics), R.A. Fisher (Mathematics of a lady tasting tea), and an article of I.M. Yaglom called Mathematics yesterday, today and tomorrow; Contemporary problems in Cybernetics, with articles by A.I. Orlov (Various applications of statistics), S.A. Aivazyan (Multidimensional statistics in socio-economic studies), Yu. N. Tyurin a.o. (Nonnumerical computer science), N.G. Zagoruiko (Some unsolved mathematical problems of applied statistics); V.I. Arnol'd, Theory of catastrophes; I.L. Bukatova, Modelling evolution: ideas, basic results and applications; N.G. Zagoruiko, Methods of detecting regularity; V.M. Gluskov, The machine proves.

But back to Arnol'd's little book. The phrase "catastrophe theory" does not have a happy ring at the moment and the (applied) field of mathematics which goes under that name did not really survive the overly harsh criticism which was leveled against especially its sociological and economic applications a number of years ago (about 10). Fortunately the meat of it, that is the solid, hard, valuable theorems, live on. And embedded in the more general setting of singularity and bifurcation theory Thom's results now find very solid applications (e.g. caustics in 
optics). This is a beautiful little book, popular mathematics at its best, a delight to read and unreservedly recommended to novice and expert alike. It is more about singularities than about catastrophes. My copy came with a letter explaining that through an oversight the book had not been proofread and promised a revised and improved second edition soon.

H.W. Knobloch and K. Schmidt (eds), Equadiff 82, Springer-Verlag, 1983, LNM 1017, 666 pp., DM 68.00.

The proceedings of a fairly large conference (some 200 participants). A fairly heterogeneous collection of articles of mostly 10 pages or less in length. Topics vary greatly: intracellular gels, fix points, reaction diffusion models, chaos in the driven van der Pol, neutral functional differential equations, Hopf and other bifurcations, statistical stability, turning points, epidemic models, semigroups of operators, integrable Hamiltonian systems and lots of other topics. Often only one highly specialized article about each of the topics named, occasionally maybe three. I am not really in favour of such collections unless together they give an accessible good state-of-the-art snapshot of a field. This one does not, although many of the authors are well known and respected and although it is certainly an instructive excercise to glance through the table of contents to gain a first impression of the many uses to which differential equations can be put.

B.A. Dubrovin, A.T. Fomenko, and S.P. Novikov, Modern geometry - methods and applications. Part I: The geometry of surfaces, transformation groups, and fields, Springer, 1984, 464 pp., DM 128.00.

B. Dubrovine, S. Novikov and A. Fomenko, Contemporary geometry - methods and applications. Part II: Geometry and topology of varieties (in French), MIR, 1982, 371 pp., FF 60.00 .

B. Dubrovin, S.P. Novikov and A.T. Fomenko, Contemporary geometry. Part III: Methods of homology theory (in Russian), Nauka, 1984, 343 pp., 2.30 roubles.

These are parts I, II, III, respectively in English translation, in French translation, and Russian original of the Dubrovin, Novikov, Fomenko three-volume treatise on modern or contemporary geometry. The Russian originals appeared in 1978, 1979 and 1984, respectively and are being reprinted. The French translation of all three volumes is now available and of the English translation, volume 1 was published in 1984, volume 2 appeared early this year or late last year and volume 3 is expected in the near future.

Together with algebraic geometry, differential geometry is one of hardest subjects to teach at university level. And, until recently, it was very difficult to find a 
suitable core text to use as a basis. For algebraic geometry this problem disappeared with the publication of a number of excellent texts (Safarevic, Harris/Griffiths, Mumford, ...) and for differential geometry I would definitely choose this three-volume treatise based on lectures given at MGU since 1971. As with $M$. Spivak's five-volume treatise, physics is presented as the main motivating force (though there is no chapter entitled "And now a message from our sponsor"). The authors have made no attempt to make the books selfcontained in that material needed from analysis, algebra, measure theory, is stated but not proved. Also, especially in volume II, III, not all proofs are given in complete detail. The authors hold, rightly in my opinion, that understanding is not dependent on exhaustive detail and that those parts of the proofs which have no bearing on applying techniques and results can, on occasion, be safely omitted or broken down into exercises. Parts II and III are a good deal more difficult and sophisticated than Part I. A glance at the chapter headings listed below will give the reader an idea of what is covered. Part I: 1 . Geometry of regions of a space: basic concepts, 2 . The theory of surfaces, 3 . Tensors: the algebraic theory, 4 . The differential calculus of tensors, 5. The elements of the calculus of variations, 6 . The calculus of variations in several dimensions. Fields and their geometric invariants. Part II: 1. Examples of manifolds, 2. Questions of justification. A reminder of the elements of the theory of functions. Typical differentiable mappings (literally translated from the French title of this chapter), 3. Degree of a mapping. Intersection number. Applications of these concepts, 4. Orientable manifolds. Fundamental group. Coverings (fibre spaces with discrete fibre), 5. Homology groups, 6. Differentiable fibre spaces, 7. Some examples of dynamical systems and of foliations on manifolds, 7. Global structure of solutions of variational problems in several dimensions. (In the last two chapters both the Korteweg-de Vries and Yang-Mills equations are discussed.) Part III: 1. Homology and cohomology: recipes and calculation, 2. Critical points of smooth functions and homology, 3. Cobordism and smooth structures.

The French translation is occasionally a bit spotty and belaboured, witness the translation of the title of chapter 2 of part II. But I have not found phrases or sentences which became totally ununderstandable. (One of the authors, though, was very unhappy about this translation and once asked me if I could not find a publisher in France itself to deal with part III.) Given the quite substantial difference in price, I would recommend individuals who can read French reasonably well to invest in this edition. The books published by MIR, Moscow, in French are not always easy to find, but the store of Presses Université de France on the Boulevard Michel usually has an almost complete selection, adding one more reason for visiting Paris occasionally. Writing directly to MIR in Moscow (U.S.S.R., Moskva, 1-i Rizskii per. 2) is not likely to produce reactions and should probably be added to the list of recreational impossibilities in the "Guide".

A new book by Novikov and Fomenko, called Elements of differential geometry and topology is scheduled to be published by Nauka in 1987. This will be sort of a 
one-volume abridged version of the present three-volume treatise. That one will also be translated into English.

\section{P. Krée and Chr. Soize, Mécanique aléatoire, Dunod, 1983, 644 pp.}

The subtitle of this book: nonlinear vibrations, seismic waves, sea waves, metal fatigue, and the front cover picture, which shows an off-shore structure buffeted by waves, clearly indicate what this is all about. Stochastic ideas and models are important and useful in all kinds of engineering including electric and structural engineering. The book, an excellent one in my opinion, has no readily visible competitors and is a solid piece of testimony to the rapidly increasing importance of stochastic ideas and techniques in applied mathematics. This does not mean that the increasing importance of stochastics is limited to this field.

An English translation of this book is planned for late 1986 (D. Reidel Publishing Company).

R. Thom, Mathematical models of morphogenesis, E. Horwood, 1983, 305 pp., $£ 25.00$.

This is the translation of Modèles mathématiques de la Morphogenèse, Chr. Bourgois, 1980, 315 pp., $140 \mathrm{FF}$, complemented with updatings and a revised chapter 9. Itself, this 1980 French edition is a drastically revised and improved version of a 1974 edition (especially the mathematical chapters). We are dealing here with Catastrophe Theory. Once praised to the heavens as the science of discontinuous changes with impressive sounding applications to almost everything and then practically murdered by some very harsh criticism. Too harsh probably (certainly in my view). The book ranges from chapters containing deep and important mathematics to articles of a philosophical/methodological bent on, e.g., semantics, linguistics and semiotics. These do not appeal very much to me personally (in spite of long-standing interests in such matters) but nothing produced by a man as original and deep-thinking as Thom can be dismissed even when one has solid and well-founded objections.

M. Kubicek and M. Marek, Computational methods in bifurcation theory and dissipative structures, Springer-Verlag, 1983, 243 pp., DM 108.00.

Mathematically speaking we are concerned here with equations (algebraic, differential, ...) depending on one or more parameters and interest focuses on changes in the solution sets as the parameter varies. An obviously most important topic to understand, both theoretically and numerically, if one wants to make use 
of the opportunities offered by nonlinear phenomena. It will be very hard to get better returns than with judicious investments or controls near a bifurcation point ("hot spot control"). Come to think of it, a world which ran on purely linear principles would be a sad and dreary place. There are a number of proceedings dealing with numerical calculation of bifurcations but no other monographs that I am aware of. In this volume the authors share with the readers their considerable experience in these matters. Though perhaps not totally up to date in all numerical aspects, it is a most valuable volume.

E. Zauderer, Partial differential equations of applied mathematics, Wiley, 1983, 799 pp., £47.50.

A.V. Bitsadze, The equations of mathematical physics, Nauka, 1982, 336 pp., 0.80 roubles.

Two upper undergraduate texts on partial differential equations. Both very early introduce three standard examples: the diffusion equation, the wave equation and the Laplace equation. There practically all similarity ceases, though the words and phrases occurring in the two indexes of the books are by and large the same. Bitsadze's book is very classical: PDE by separation of variables and integral transforms; Fourier series, eigenfunction expansions, special functions, Sturm-Liouville theory, Laplace and Fourier transforms. The style derives equation after equation, theorem after theorem. There is no discussion of ideas or guiding principles. It contains even less physics than Zauderer's book in so far as that is possible.

Zauderer's book contains all the above in one way or another and also much more including adequate coverage of numerical aspects, a great deal of material on perturbation and asymptotic methods and a quite original probabilistic derivation of the three equations named above as a continuum limit.

There is little doubt that I would enjoy teaching a course on the basis of Zauderer's book.

There is an English translation of the Bitsadze book published by MIR at 1.65 roubles which even at the bookseller conversion rate of 3 to $4 \$$ per rouble (the official exchange rate is about $\$ 1.25=1$ rouble; the unofficial one $\$ 1.00=2.50$ roubles) works out at a very reasonable price. There is also a probably much more useful companion volume of exercises. However, except as an absolute emergency measure for very poor students, I can see but little reason for purchasing the Bitsadze book.

A.P. Zelobenko and A.I. Stern, Representations of Lie groups, Nauka, 1983, 360 pp., 1.50 roubles.

A 158-page basic concise introduction to representation theory of finite dimensional Lie groups, followed by a compendium (more or less) of concrete represen- 
tations. A very useful volume containing for its size an enormous amount of information. It has, in Moscow, a high reputation. So much so that three different friends of mine considered it the natural book to present me with. No translation contract appears to have been signed which is a pity as it would be a very valuable addition to any major series of textbooks.

A.J. Jerri, Introduction to integral equations with applications, M. Dekker, 1985, 254 pp., $\$ 39.75$ (U.S.A. and Canada), $\$ 47.50$ (all other countries).

The habit of some American publishers to charge some $25 \%$ more to customers outside the U.S.A. and (anada (even when they pay with a cheque in U.S. $\$$ drawn on an American hank is an abomination. It irritates me so much that it introduces a nontrivial and far from objective bias in my advice to libraries and others and it certainly also seriously influences my own buying habits.

With this boxk the author has attempted to write a text on integral equations at the same level as an ordinary first course on ordinary differential equations. The author holds, rightly in my view, that integral equations are really becoming much more important and are more versatile, more fundamental, and more suitable for machine computation. Thus, they should be introduced in the curriculum as early as possible. He also wanted to present his material in an applicationsmotivated way and in this he succeeds admirably. Other aspects indicate that the book should have been tested out on students a few more times. As it stands it is a most usable introduction to the field for mature mathematicians who know nothing or little about integral equations but seems less suitable for students.

V.Yu. Arsenin. The metheds of mathematical physics and special functions, Nauka, $1984,38.3 \mathrm{pp} ., 1.10$ roubles.

There used to be a time, as I had sccasion to write some two years ago (Series editor's preface to R.A. Askey, T.H. Koornwinder, W. Schempp (eds), Special functions: group theoretucal aspects and applications, D. Reidel, 1984), when every (applied) mathematician and physicist knew at least a large chunk of special function theory and used this knowledge regularly. Then came a period of decline, when being interested in special functions was almost a symptom of some derangement or mania, and then special functions moved back to a place in the centre of things via Vilenkin's magnificent discovery of the links between special functions and representation theory.

$S o$ the title of this boxk sounded highly promising. Mathematical physics, special functions, hence symmetries, etc., etc., potentially very attractive. What we have instead is a $b(x) k$ consisting of two practically separate parts. Part I on the basic methods of mathematical physics (and setting up the problems) and part II on special functions in a very old fashioned way. Very disappointing. 
A.A. Markov and N.M. Nagornyi, Theory of algorithms, Nauka, 1984, 432 pp., 3.30 roubles.

The final and definitive book on the deep and fundamental work by the senior author A.A. Markov (1903-1979). Incidentally this is not the Andre Andreevic Markov of Markov chains but his son. A translation of this book will be published by D. Reidel Publishing Company.

Th.M. Liggett, Interacting particle systems, Springer-Verlag, 1985, 488 pp., DM 196.00.

At the recent first world congress of the Bernoulli Society, one of the invited speakers on interacting particle systems started his remarks as follows: "Dobrusin is the father of our subject, some of the most interesting current results are being done by Presutti and the ideal book to use to get introduced to the subject is the one by Liggett". Little more needs to be said, beyond remarking that the study of interacting particle systems turned out to require totally new ideas and techniques in probability making the field and this book doubly interesting.

Michiel Hazewinkel

Bussum, September, 1986 